\title{
COMPUTER SIMULATION OF A BIVALENT HEATING INSTALLATION
}

\author{
JACQUES NICOLAS and JEAN-POL PONCELET \\ Fondation Universitaire Luxembourgeoise, Arlon, Belgium
}

(Received 10 August 1984; received for publication March 1985)

\begin{abstract}
A computer simulation program for a dwelling heating installation has been developed and tested. It uses basic principles and defined parameters, with simplifications to reduce the program size and execution time. Integration of the differential equations describing the heat transfer in the system is performed with constant time steps (explicit scheme). The program is utilized to study the performance of the heating system and to perform parametric studies to determine the effects of changes in various parameters on performance. The influence of the time increment, thermal insulation, heat capacity and of other parameters on system performance has been analyzed. Included in the regulation software of a control system, the program is a design tool to optimize regulation and help in developing and testing modern regulators.
\end{abstract}

\section{INTRODUCTION}

In a heating system, the major problem is to make the correct choice of the most appropriate source of energy at the right time. This goal can be reached by using a suitable control system that performs the functions of a smart thermostat: regulation, decision-making, energy saving, comfort optimization. To test various algorithms for this controller, it is useful to operate a model with behaviour similar to that of a real heating system, so that any parameter may be modified at any time. In the model, a computer program to code heat-transfer equations is used with numerical approximation to simulate the heating installation.

This study describes a simulation program developed in Pascal language (on an Apple II computer) that is compatible with a microprocessor regulation software which we initially developed in Pascal. It was designed to interface and operate with an actual regulation system. The paper focuses on the first step in the design of a microprocessor-based blackbox simulation. It does not describe the program but is restricted to the mathematical models used in the program. A detailed description of the subsystems equations is given in Appendix A.

\section{PURPOSE AND SCOPE OF THE SIMULATION}

The simulation program presented in this paper is aimed at testing control algorithms and regulation systems. The microcomputer module is planned to provide control designers and heating-system specialists with an easy tool to check reliability in terms of energy cost and comfort. Consequently, the purpose of the simulation is not a detailed description of the actual system behaviour with many parameters. The analysis results in a simple model for an actual heating installation. The small size of the program allows implementation on a personal computer or a microcomputer system with little memory space and long execution time. This procedure requires simplification, but our model is suitable for a description of relative thermal behaviour in testing control algorithms. The purpose and scope are different from the modular approach and iterative scheme used in a simulation code such as TRNSYS, which is basically devoted to solar energy-system design. ${ }^{1}$

The temperature evolution with time is defined by the model, as are also the command of valves, pumps, compressor and burner, which are the major active parts of the installation. The outside temperature and insolation are simulated for typical days in the year, thus allowing the user to create any desired sequence of climatic conditions. With the addition of a heating flux to the room-temperature model, some passive solar effects may be easily handled (mainly direct solar gain), as well as some consequences of the occupant's behaviour (e.g., energy used by household appliances). Other effects of the building configuration such as sun motion, shading and blinding, forced ventilation, are not handled by the model. The 
control algorithm determined by the user is chosen in a software library, or else is directly issued by a real time regulator. Finally, simulation yields the energy cost and the room temperature.

\section{SYSTEM CONFIGURATION}

Theoretically, the behaviour of any heating system could be simulated by a correct combination of modular subsystems (e.g., a water storage tank, a three-way valve, a fuel boiler, a radiator). As the application of the method raises difficulties we prefer to fit a typical configuration to each case. For example, the system shown in Fig. 1 consists of a fuel boiler in conjunction with an air-water heat pump. This heating system feeds three separate circuits with three circulating pumps. In the first circuit the hot water temperature can be homogenized by a convection pump. In the second circuit, there is a relief valve in parallel with the radiator. The flow rate in the main circuit is therefore independent of the thermostatic valve position. In the third circuit, the correct temperature in the floor heating panels is obtained by a 3-way mixing valve. We consider a single heating body in a single room which simulates the whole dwelling. If required, the radiator and the floor heating panels may be located in the same room. It is easy to fit 3 or 4 similar configurations to most systems. For example, we developed the model of a system with solar collectors coupled with a water storage tank and a heat pump.

\section{GENERAL ASSUMPTIONS IN THE MATHEMATICAL MODEL}

Some general hypotheses are made in order to limit the number of parameters. First, the losses in the distribution system are weak compared with the heat transfer in the subsystems (we consider that the pipes are well insulated). Then, the flow rate at the outlet of a 3-way mixing valve is a linear function of the control action $V$.

In Fig. 2, the flow rates are

$$
\begin{aligned}
& \dot{m}_{1}=\dot{m}_{\text {in }} V, \\
& \dot{m}_{2}=\dot{m}_{\text {in }}(1-V) .
\end{aligned}
$$

ROOM 1 WITH RADIATOR

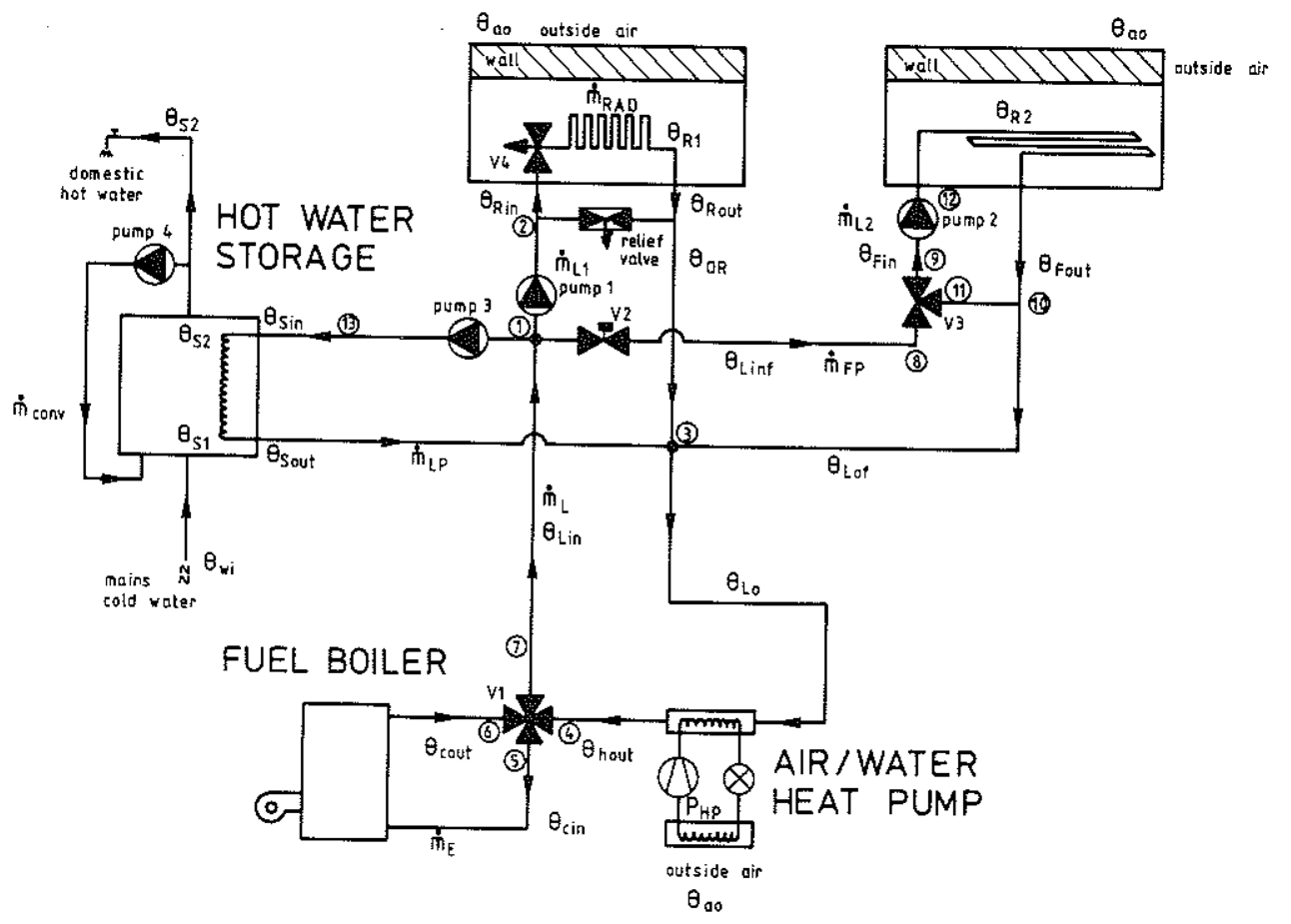

ROOM 2 WITH FLOOR HEATING

Fig. 1. Schematic diagram of a heating system, including a fuel burner, a heat pump and two heated 


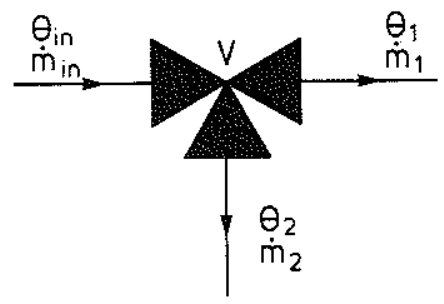

Fig. 2. A three-way mixing valve with external command $V$.

The temperatures are $\theta_{1}=\theta_{2}=\theta_{\text {in }}$. The non-linear behaviour of an actual mixing valve can be described by a relation between the control action and the linear variable $V$.

The exchange between the water flowing in a pipe and the water at rest in a tank (Fig. 3 ) is given by

$$
\left(\theta_{i}-\theta_{0}\right)=\left(\theta_{i}-\theta_{s}\right) \xi
$$

where $\xi$, a constant heat-exchanger efficiency, is defined as the ratio of the actual to the maximum heat transfer.

\section{CLIMATIC CONDITIONS}

Solar collectors or passive components in a dwelling require the modelling of the insolation. The variations of the outside temperature and insolation are simulated by periodical waveforms. $^{2,3}$ A typical daily insolation period is defined for 12 days illustrating the 12 months of the year. The mean daily solar power during this period is used to describe the instantaneous power,

$$
\begin{aligned}
& H_{T}=(\pi / 2) \bar{G} \cos [\pi(t-12) / P]\{1-\sin [K \pi(t-12) / P]\} \\
& \text { for } \quad(12-P / 2) \leqslant t \leqslant(12+P / 2), \quad H_{T}=0 \text { otherwise, }
\end{aligned}
$$

where $t$ is the time in hours (midnight is zero), $P$ is a typical daily insolation period in the month (hours), the mean solar power during the typical day of the month, $\bar{G}$, is the energy flux density $\left(\mathrm{W}-\mathrm{m}^{-2}\right), K$ is a dimensionless intermittency factor $(-), H_{T}$ is the instantaneous solar energy flux density at the time $t$ in the day $\left(\mathrm{W}-\mathrm{m}^{-2}\right)$. The outside air temperature is

$$
\theta_{\mathrm{ao}}=\left\{\left(\theta_{\mathrm{ao} \max }+\theta_{\mathrm{ao} \min }\right)-\left(\theta_{\mathrm{ao} \max }-\theta_{\mathrm{ao} \min }\right) \sin [\pi(t+4) / 12]\right\} / 2
$$

where $\theta_{\mathrm{ao}}$ is the outside air temperature, $\theta_{\mathrm{ao} \max }$ and $\theta_{\mathrm{ao} \min }$ are the maximum and minimum outside temperatures during the month. The mean values of $\bar{G}, \theta_{\text {ao } \max }, \theta_{\text {ao } \min }, P$ can be tabulated for any location and every month of the year.

\section{FLOW RATES}

The flow rate supplied by a pump varies with the pressure difference at its extremities. It is determined by the operating point at the intersection of the pump and pressure drop curves. The pressure drop in a straight pipe or in any resistance is

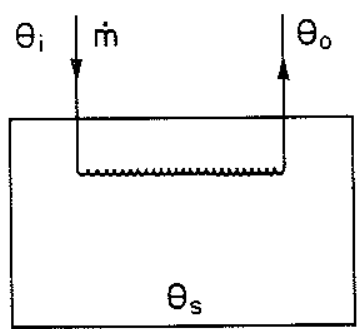

Fig. 3. Diagram and symbols used for the heat exchanger in a water tank. 


$$
R=\mathrm{K} \dot{m}^{2}
$$

where $\mathrm{K}$ is a constant for the resistance $\left(\mathrm{kg}-\mathrm{m}^{-1}\right)$ and $\dot{m}$ is the mass flow rate through it $\left(\mathrm{kg}-\mathrm{s}^{-1}\right)$. For example, with a 3 -way mixing valve (Fig. 4), the three flow rates $\dot{m}_{1}, \dot{m}_{2}, \dot{m}_{3}$ vary according to the valve position $V$ and are

$$
\begin{aligned}
& \dot{m}_{1}=V \dot{m}_{c}+(1-V) \dot{m}_{0}, \\
& \dot{m}_{2}=(1-V) \dot{m}_{0}, \\
& \dot{m}_{3}=V \dot{m}_{c} .
\end{aligned}
$$

In the heating system of Fig. 1, 6 flow rates depend on 2 valves and 3 pumps in the main circuit. If we use second order polynomes to describe the circuit pressure losses (Eq. 6) and the pumps' characteristics (pressure-flow rate), we create first and second order terms. As the equations must be solved for each time step the simulation is complex and slow. Hence the pumps' characteristics and the pressure losses are described by a first order function of the flow rate. The linearity is good near the operating point. The pressure drop in the pump is

$$
\Delta p=A+B \dot{m},
$$

where $A(\mathrm{~Pa})$ and $B\left(\mathrm{~m}-\mathrm{s}^{-1}\right)$ are constant. The pressure loss in a resistance is

$$
\Delta p=\mathrm{K} \dot{m}
$$

where $\mathrm{K}$ is a constant for the resistance $\left(\mathrm{m}-\mathrm{s}^{-1}\right)$. For the heating system of Fig. 1, the user chooses the $A$ and $B$ coefficients of the pumps $P_{1}, P_{2}$ and $P_{3}$ and calculates the resistance of the different branches in the circuit. These resistances are given as a multiple of a unit resistance $R$, which is the pressure loss in one meter of a standard pipe. ${ }^{4}$ Before the simulation the 6 flow rates $\dot{m}_{L 1}, \dot{m}_{L 2}, \dot{m}_{F P}, \dot{m}_{L}, \dot{m}_{E}, \dot{m}_{L P}$ are computed for the 4 situations $V 1=0$ and $V 3=0, V 1=1$ and $V 3=0, V 1=0$ and $V 3=1, V 1=1$ and $V 3=1$. During the simulation each flow rate is calculated as in Eq. (7) according to the $V 1$ and $V 3$ values. The valve $V 4$ is not considered here. The pressure loss is constant in the subsystem radiator-relief valve. If a pump is stopped by the control procedure the corresponding $B$ coefficient in Eq. (10) increases, and the calculated flow rate is nearly zero. If $\dot{m}_{L 1(01)}$ is the flow rate $\dot{m}_{L 1}$ when $V 1=0$ and $V 3=1$ (and so on for $\dot{m}_{L !(i j)}$ ) the general expression of $\dot{m}_{L 1}$ is$$
\dot{m}_{L 1}=V 3\left[V 1 \cdot \dot{m}_{L 1(11)}+(1-V 1) \cdot \dot{m}_{L 1(01)}\right]+(1-V 3)\left[V 1 \cdot \dot{m}_{L 1(10)}-(1-V 1) \cdot \dot{m}_{L 1(00)}\right] .
$$

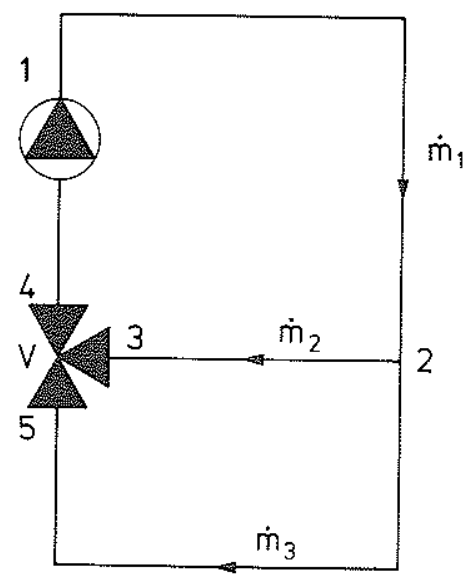

Fig. 4. Piping circuit showing three flow rates varying with the valve position. 
When mixing occurs the calculation of the resulting temperature relies on the conservation of the product of the flow rate and the temperature.

\section{FUEL BOILER}

The fuel boiler supplies heat to the water circuit (Fig. 5). The boiler consists of a metal body and a water content at temperature $\theta_{B}$ in an environment at room temperature $\theta_{R 1}$. The hot water at temperature $\theta_{B}$ flows at the rate $\dot{m}_{E}$. The heat balance of the boiler depends on the boiler power, the heat transmitted to hot water, the convection with the ambient air, and the increase of the internal energy of the metal-water system at uniform temperature $\theta_{B}$ (see Appendix).

The fuel consumption is calculated from the fuel power density $E_{B}\left(\mathrm{~kJ}^{\mathrm{J}} \mathrm{kg}-\mathrm{l}\right)$, the fuel density $\rho_{B}(\mathrm{kg-m}-3)$ and the boiler efficiency $\eta_{B}(-)$. The rate of fuel consumption $\left(\mathrm{dm}^{3}-\mathrm{s}^{-1}\right)$ is

$$
F_{B}=P_{B} / \eta_{B} \rho_{B} E_{B}
$$

\section{HEAT PUMP}

An air-water type heat pump can be included in the system configuration (Fig. 6). The heat pump transfers heat from the outside air at temperature $\theta_{\mathrm{ao}}$ to the water flowing at a rate $\dot{m}_{L}$ and temperatures $\theta_{L 0}$ and $\theta_{H \text { out }}$.

\section{RADIATOR}

The nominal temperature difference between the water in the radiator and the ambient air is $\left(\theta_{H}-\theta_{R 1}\right)_{N}$. Then the heating power is $\dot{Q}_{N}$ and the steady state heating power $\dot{Q}$ of the radiator is ${ }^{4}$

$$
\dot{Q}=\dot{Q}_{N}\left[\left(\theta_{H}-\theta_{R 1}\right) /\left(\theta_{H}-\theta_{R 1}\right)_{N}\right]^{m}
$$

The water temperature in the radiator is the mean of the temperatures at the inlet and the outlet of the radiator

$$
\theta_{H}=\left(\theta_{R \text { in }}+\theta_{R \text { out }}\right) / 2
$$

According to different tests ${ }^{4}$ the exponent $m$ is $4 / 3$. The nominal power and temperatures are either program parameters or the result of the calculation of the dwelling heat losses.

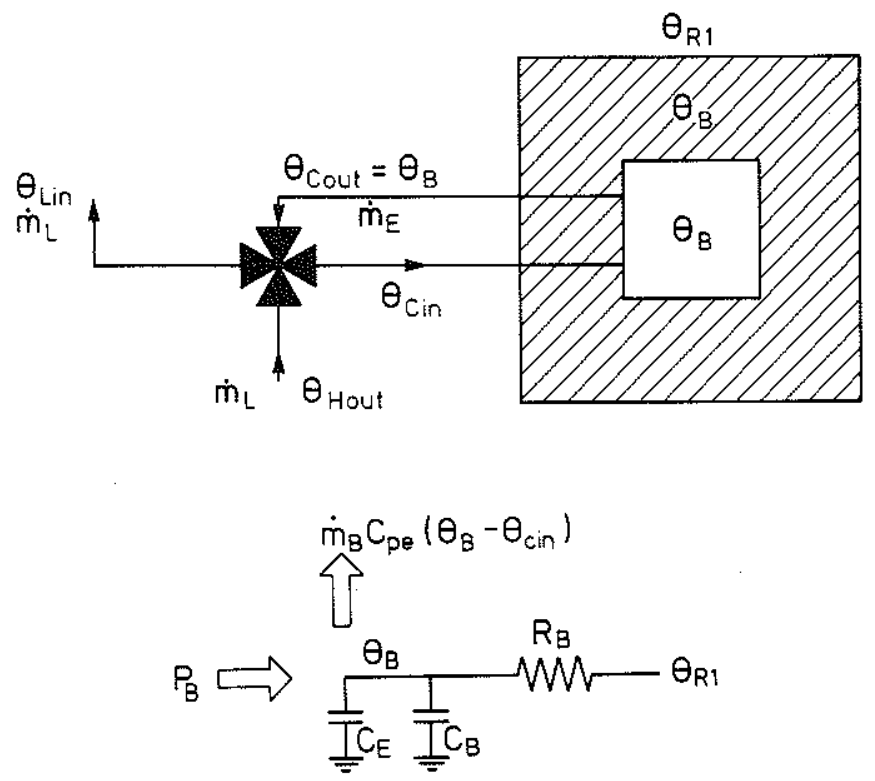

Fig. 5. a) The boiler configuration for the heating plant described in the paper and b) its electrical analogy. 


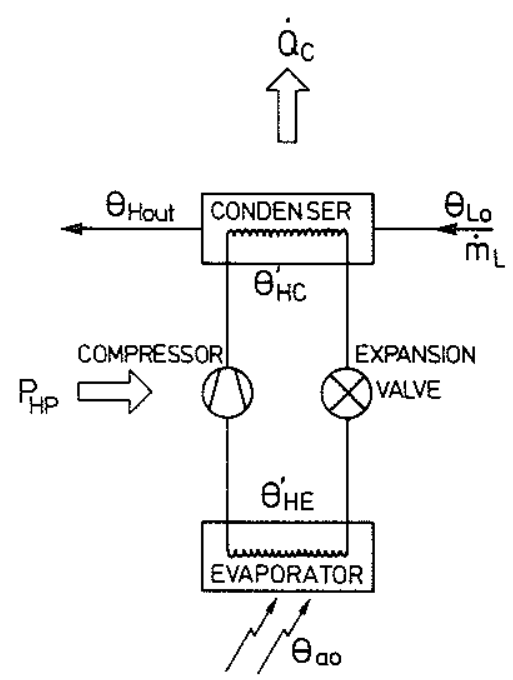

Fig. 6. The model of the air-water type heat pump used in the simulation.

The model deals with the dynamic behaviour of the radiator, as its temperature is increased by the heat dissipation.

\section{THERMOSTATIC VALVE}

We assume that the total mass flow rate $\dot{m}_{L 1}$ is independent of the valve position (Fig. 1). The model of the flow rate $\dot{m}_{\mathrm{RAD}}$ in the radiator is linear in the range $\left[\theta_{\mathrm{RSET}}-\theta_{\mathrm{TV}}\right.$, $\left.\theta_{\mathrm{RSET}}\right]$, where $\theta_{\mathrm{TV}}$ is the temperature range of the valve $(\mathrm{K})$ and $\theta_{\mathrm{RSET}}$ is the set point $\left({ }^{\circ} \mathrm{C}\right)$. The remaining flow rate $\left(\dot{m}_{L 1}-\dot{m}_{\mathrm{RAD}}\right)$ is assumed to pass through the relief valve.

\section{FLOOR HEATING}

The model of the radiator (Eq. 14) is used for describing the floor heating in room \#2. The exponent is then 1 . The heat capacity of the floor is computed for a given thickness of a concrete floor.

\section{HOT WATER STORAGE}

The water temperature is not uniform in the storage tank. There is a vertical stratification with a continuous variation of the water temperature and density, provided that the water flows in at a low velocity. ${ }^{5}$ The storage behaves as if a fictitious valve $(\gamma)$ let water flow in where it can mix with water at the same temperature. The temperature of the cold water at the inlet is constant and we assume that the system operates at a constant mass flow rate $\dot{m}_{\text {SAN }}$. Energy balances can then be calculated for some vertical sections of the tank. The hot water consumption results from the dweller's way of life.

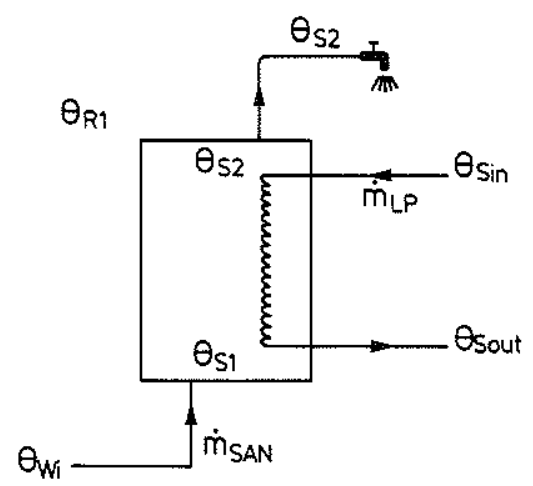

Fig. 7. The model of the domestic hot water storage. An energy balance is written for two vertical sections of the tank. 


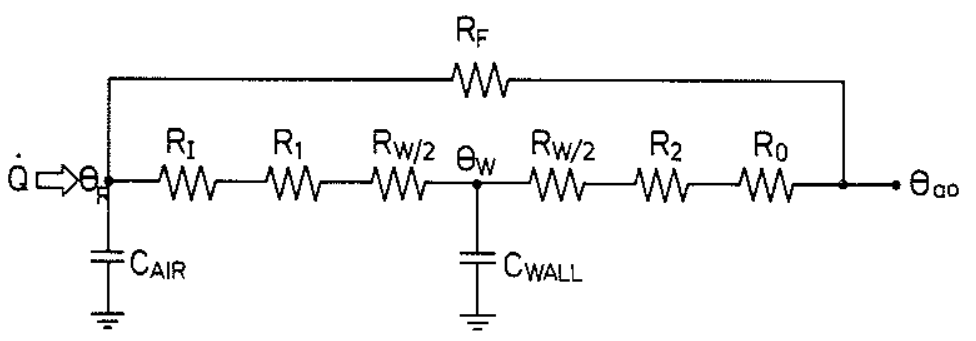

Fig. 8. The electrical analogy used in the model of the rooms.

\section{ROOMS}

The dwelling consists of two rooms (Fig. 1) heated by the system, according to the electrical analogy of Fig. 8 . The room temperature $\theta_{R}(t)$ depends on the thermal behaviour of the walls. The model describes heat convection on both sides, and heat conduction in the wall and in the thermal insulation material. In each case, the program calculates the thermal resistances $R_{i}$ [(W-K $\left.\mathrm{K}^{-1}\right)^{-1}$ ] depending on the properties of the material; e.g., thickness and surface, thermal conductivity, heat transfer. The model describes the wall thermal inertia as a function of its thermal capacity.

\section{THE COMPUTER PROGRAM}

The model of the heating system is used in a simulation program on a personal computer (PASCAL language). The program must be included in the regulation software of a control

Table 1. System dimensions.

\begin{tabular}{|c|c|c|}
\hline heated volume & $m^{3}$ & 300 \\
\hline thermal losses without insulation & $\mathrm{W} / \mathrm{K}$ & 389 \\
\hline $\begin{array}{l}\text { thermal conductance of the } \\
\text { non-insulated wall }\end{array}$ & $W / m^{2} K$ & 1.7 \\
\hline $\begin{array}{l}\text { heat capacity of the walls } \\
\text { case } 1 \\
\text { case } 2 \\
\text { case } 3\end{array}$ & $\mathrm{MJ} / \mathrm{K}$ & $\begin{array}{l}15.6 \\
42.0 \\
79.5\end{array}$ \\
\hline nominal outside / inside temperature & ${ }^{\circ} \mathrm{C}$ & $-15 / 20$ \\
\hline $\begin{array}{l}\text { fuel burner : } \\
\text { water content } \\
\text { cast iron } \\
\text { thermal losses }\end{array}$ & $\begin{array}{l}\mathrm{kg} \\
\mathrm{kg} \\
\mathrm{W} / \mathrm{K}\end{array}$ & $\begin{array}{l}30 \\
150 \\
25\end{array}$ \\
\hline $\begin{array}{c}\text { climatic conditions (february) } \\
\text { minimum outside temperature } \\
\text { maximum outside temperature }\end{array}$ & ${ }^{\circ} \mathrm{C}$ & $\begin{array}{l}-2.3 \\
4.8\end{array}$ \\
\hline \multicolumn{3}{|c|}{$\begin{array}{l}\text { regulation : } \\
\text { - on-off room thermostat set at } 20^{\circ} \mathrm{C} \text { with } 0.5^{\circ} \mathrm{C} \text { hysteresis } \\
\text { acting on fuel burner and on circulating pump; } \\
\text { - thermostatic valve not used } \\
\left.\text { (set point }=50^{\circ} \mathrm{C}\right)\end{array}$} \\
\hline
\end{tabular}




\begin{tabular}{|c|c|c|c|c|c|c|c|c|}
\hline 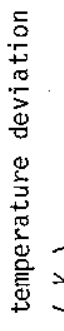 & & $\begin{array}{l}8 \\
0\end{array}$ & $\begin{array}{l}8 \\
0\end{array}$ & $\overrightarrow{0}$ & $\stackrel{\widetilde{\sigma}}{\circ}$ & đِ & $\begin{array}{l}\infty \\
0 \\
0\end{array}$ & $\stackrel{m}{\text { m}}$ \\
\hline \begin{tabular}{c}
- \\
0 \\
- \\
0 \\
\multirow{2}{*}{}
\end{tabular} & 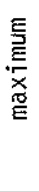 & $\begin{array}{l}8 \\
\stackrel{0}{0}\end{array}$ & $\begin{array}{l}8 \\
\dot{0} \\
\text {. }\end{array}$ & $\begin{array}{l}\stackrel{8}{ } \\
\stackrel{\sim}{ }\end{array}$ & $\overrightarrow{\grave{D}}$ & $\begin{array}{l}\text { oे } \\
\dot{\sim}\end{array}$ & ণ্ড & 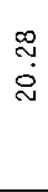 \\
\hline 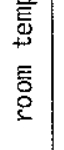 & 焉 & $\begin{array}{l}8 \\
\dot{N}\end{array}$ & $\begin{array}{l}8 \\
\stackrel{0}{0}\end{array}$ & $\begin{array}{l}\text { ᄋे } \\
\text { 욤 }\end{array}$ & $\begin{array}{l}\text { ㅇ } \\
\text { oे }\end{array}$ & 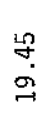 & 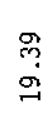 & $\begin{array}{l}\stackrel{\sim}{N} \\
\stackrel{\sigma}{\sigma}\end{array}$ \\
\hline 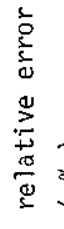 & co & $\stackrel{\ddot{0}}{0}$ & $\dot{0}$ & $\stackrel{\infty}{\infty}$ & $\stackrel{\infty}{0}$ & $\stackrel{?}{-}$ & $\dot{m}$ & $\stackrel{\infty}{\infty}$ \\
\hline 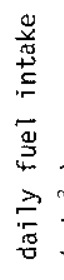 & E & مُ & $\stackrel{\dot{\omega}}{\dot{\omega}}$ & $\stackrel{m}{\stackrel{m}{v}}$ & $\begin{array}{l}m \\
\stackrel{w}{N}\end{array}$ & $\begin{array}{r}\dot{D} \\
\stackrel{D}{0}\end{array}$ & مُ & $\stackrel{q}{\tilde{N}}$ \\
\hline 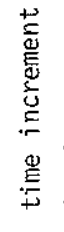 & 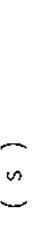 & $\rightarrow$ & $\sim$ & مـ & 엉 & 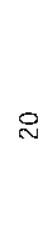 & 8 & 刃్తి \\
\hline
\end{tabular}


Table 3. Influence of house insulation on system performance. The boiler power is $30 \mathrm{~kW}$ and the room thermostat is set to $20^{\circ} \mathrm{C}$.

\begin{tabular}{|c|c|c|c|c|}
\hline \multicolumn{2}{|c|}{$\begin{array}{l}\text { thermal conductance } \\
\left(\mathrm{W} / \mathrm{m}^{2} \mathrm{~K}\right)\end{array}$} & $\begin{array}{l}\text { thermal losses } \\
(\mathrm{W} / \mathrm{K})\end{array}$ & $\begin{array}{l}\text { nominal heating power } \\
(\mathrm{KW})\end{array}$ & $\begin{array}{l}\text { daily fuel consumption } \\
\left(\mathrm{dm}^{3}\right)\end{array}$ \\
\hline \multicolumn{2}{|c|}{ insulation } & wal1 & & \\
\hline \multirow{2}{*}{1000} & 1.7 & 389 & 13.6 & 26.1 \\
2 & 0.9 & 242 & 8.5 & 17.3 \\
1.5 & 0.8 & 217 & 7.6 & 15.8 \\
1.0 & 0.6 & 183 & 6.4 & 13.9 \\
0.8 & 0.5 & 165 & 5.8 & 12.6 \\
0.5 & 0.4 & 131 & 4.6 & 10.8 \\
0.2 & 0.2 & 86 & 3.0 & 8.4 \\
0.1 & 0.1 & 67 & 2.3 & 7.2 \\
\hline
\end{tabular}

system. It gives the response of a dwelling heating system and allows to test various algorithms of the regulation process. The integration of the differential equations is performed by the Euler formula (explicit scheme) with a constant integration step. This method is valid as long as the time increment (i.e., the integration step) is kept smaller than the shorter response time of the whole subsystem. As we deal here with first order equations with decreasing exponential solutions the time increment must be smaller than the time constant of the exponential solution.

\section{DISCUSSION}

The behaviour of a dwelling heating system is strongly dependent upon the regulation procedure issued by the control system. The energy required and the thermal comfort produced by a fuel-burner system are different if, instead of a room thermostat, we use thermostatic valves and a microprocessor-based regulation of the temperature. Answering these problems is precisely the main long term objective of this task. The discussion concentrates here upon the parametric sensitivity of the model. We investigate its response to changes in some important parameters. Further work will focus on the consequences of regulation improvements on a given system.

The dimensions and parameters used in the reference system to validate the basic behaviour of well known elements are listed in Table 1. The analysis is made for a short time period illustrating the winter conditions. As the initial room temperature conditions may influence the system transient behaviour, we report steady-state results after one day.

\section{(a) Time increment}

We studied the influence of the selection of the integration time-step on the system's performance. The results are listed in Table 2 (the large oversizing of the boiler power at $30 \mathrm{~kW}$ results from a simultaneous sensitivity analysis with the same data and must not be attributed to the model). The time increment varies from 1 to 120 seconds. The performance in terms of daily fuel consumption and room temperature is calculated. We note a discrepancy on fuel consumption of about $10 \%$ between the minimum value required with the minimum time step. We see a progressive increase of the room temperature variation on either sides of the set point of the regulator (actually a room thermostat). This effect amounts to $1.30 \mathrm{~K}$ at $20^{\circ} \mathrm{C}$ with a $120 \mathrm{~s}$ time step. No variation is measured with a $1 \mathrm{~s}$ step.

It is interesting to compare the requirements of the stability criterion in the numerical integration with the operating conditions of the model. In the present case the actual time step can not exceed one half of the value issued bv the calculation (i.e.. $40 \mathrm{~s}$ instead of 80 


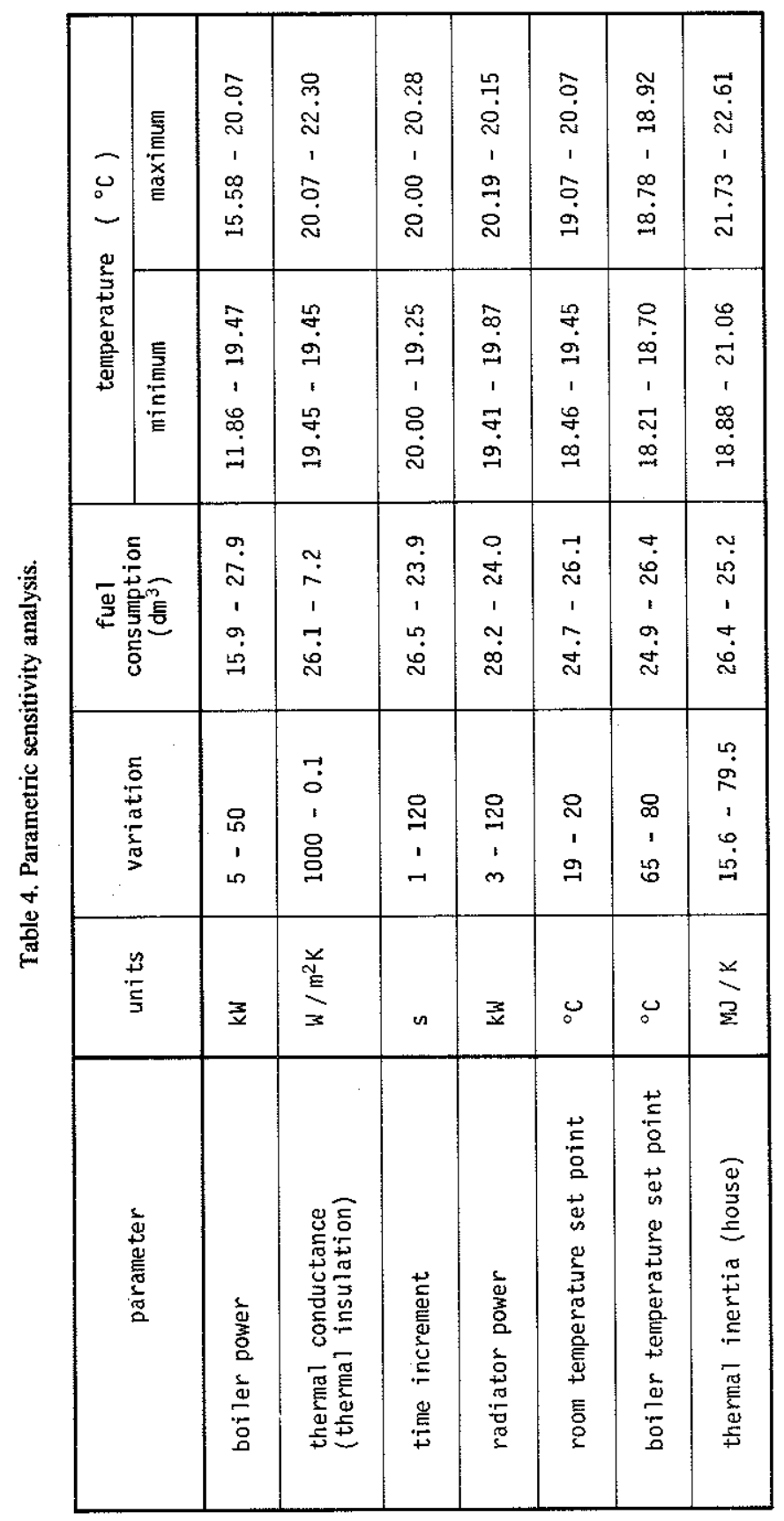


s). As shown in the table, this is a good balance between the need for accuracy and a short computing time.

\section{(b) House insulation}

The model correctly describes the influence of the house thermal insulation. A parametric sensitivity analysis of the thermal resistance coefficient was made (see Table 3 ). The system performance was calculated with a variation from $1000 \mathrm{~W} / \mathrm{m}^{2}-\mathrm{K}$ to $0.1 \mathrm{~W} / \mathrm{m}^{2}-\mathrm{K}$ of the thermal conductance of the insulation material. (Note that the non-insulated wall conductance in the case referred to is $1.7 \mathrm{~W} / \mathrm{m}^{2}-\mathrm{K}$. With a $0.05 \mathrm{~m}$-thick rockwool layer at the wall inner side it is $0.8 \mathrm{~W} / \mathrm{m}^{2}-\mathrm{K}$ ). Comparison of the $1.7 \mathrm{~W} / \mathrm{m}^{2}-\mathrm{K}$ wall (i.e., without insulation) and the moderately insulated wall $\left(0.8 \mathrm{~W} / \mathrm{m}^{2}-\mathrm{K}\right)$ yields a reduction of $26.1 \mathrm{dm}^{3}$ from the daily fuel consumption, i.e., a $40 \%$ decrease.

\section{(c) Other parameters}

We tested the sensitivity of the model to variations of the house thermal inertia in the three referenced cases, respectively at $15.6,42.0$ and $79.5 \mathrm{MJ} / \mathrm{K}$. The increase of the inner heat capacity in the house yields a $5 \%$ gain in the steady-state fuel consumption. Of course the transient behaviour is influenced by the higher inertia resulting from an increased heat capacity.

A summary of the other results is shown in Table 4. We notice that some parameters are responsible for most variations of the performance. The heat losses in the pipes and the thermal inertia of the boiler have a weak action on the performance, whereas the boiler power and the house insulation contribute to major variations.

\section{CONCLUSIONS}

A model of a bivalent heating plant has been described and discussed. The model was introduced in a small size computer code. The heat-transfer equations are solved by numerical approximation methods. The system performance was estimated by the energy consumption and the room temperature. A parametric sensitivity analysis was made with a reference system to validate the basic behaviour of the different subsystems. The most important parameters were identified and the response of the system was investigated. The program is designed to be included in the regulation software of a control system and to test various algorithms in the regulation process. The program can be used on a real time basis in the development of control systems.

Acknowledgements - We are indebted to the Commission of the European Communities for financial support under E.E.C. regulation 1996/79, contract C (80) 1649, and to STERIALUX, S.A., Luxembourg, for their contribution to the research.

\section{REFERENCES}

1. TRNSYS, “A transient simulation program," Solar Energy Lab. Rep. no. 38, University of Wisconsin, Madison, Wisconsin, February (1978).

2. P. Dorato and H. K. Knudsen, Automatica 15, 673 (1979).

3. D. J. Close, Solar Energy 11(2), 112 (1967).

4. H. Rietschell and W. Raiss, Traité de chauffage et de climatisation, Dunod, Paris (1978).

5. J. A. Duffie and W. A. Beckman, Solar Energy Thermal Processes, Wiley, New York (1974).

\section{APPENDIX: DEVELOPMENT OF THE SUBSYSTEMS MODELS}

The heat balance for the boiler configuration in the heating plant of Fig. 5 is

$$
P_{B}-\dot{m}_{E} c_{W}\left(\theta_{B}-\theta_{C \text { in }}\right)-\alpha A\left(\theta_{B}-\theta_{R 1}\right)=\left(m_{W} c_{W}+m_{B} c_{B}\right)\left(\mathrm{d} \theta_{B} / \mathrm{d} t\right)
$$

where $\dot{m}_{E}$ is the mass flow rate in the water circuit $\left(\mathrm{kg}-\mathrm{s}^{-1}\right), c_{W}$ and $c_{B}$ are, respectively, the water and metal heat capacity $\left(\mathrm{J}-\mathrm{kg}^{-1}-\mathrm{K}^{-1}\right), \theta_{C \text { in }}$ is the water input-temperature $\left({ }^{\circ} \mathrm{C}\right), \alpha$ and $A$ are, respectively, the convective heat transfer coefficient $\left(\mathrm{W}-\mathrm{m}^{-2}-\mathrm{K}^{-1}\right)$, and the net outside area of the boiler $\left(\mathrm{m}^{2}\right), m_{W}$ and $m_{B}$ are, respectively, the water and metal content of the boiler $(\mathrm{kg}), t$ is time (s). The thermal resistance $R_{B}$ is the convection resistance between the metal and the outside air. The resistances between water and metal and of metal itself are neglected (see the electrical analogy in Fig. 5). The power $P_{B}$ is zero if there is no boiler or if the burner is switched off. The temperatures $\theta_{C \text { in }}$ and $\theta_{L}$ in of the water flow in the 4-way mixing valve are estimated with the rules defined previously. When the valve is closed, the boiler is not active in the heating circuit.

In the heat pump (Fig. 6), the heat transfer rate $\dot{Q}_{c}$ (W) to the water circuit is given by 
where COP stands for the coefficient of performance and $\theta_{H E}^{\prime}$ and $\theta_{H C}^{\prime}$ are, respectively, the freon absolute temperatures at the evaporator and condenser sides. In an actual cycle, with a multiplicative factor $K_{H}(\simeq 0.5)$,

$$
\mathrm{COP}=K_{H}\left(\theta_{H C}+273\right) /\left(\theta_{H C}-\theta_{H E}\right)
$$

with temperatures in ${ }^{\circ} \mathrm{C}$. Assuming a constant temperature difference between freon and the outside air in the evaporator $\left(\Delta_{E}\right)$ and between freon and the water outlet in the condenser $\left(\Delta_{C}\right)$,

$$
\begin{aligned}
& \theta_{H E}=\theta_{\mathrm{ao}}-\Delta_{E}, \\
& \theta_{H C}=\theta_{H \text { out }}+\Delta_{C} .
\end{aligned}
$$

The heat transfer rate to the water is

$$
\dot{Q}_{c}=\dot{m}_{L} c_{W}\left(\theta_{H} \text { out }-\theta_{L 0}\right)
$$

Combining Eqs. (A2) to (A6) yields

$$
\theta_{H \text { out }}^{2}+C_{1} \theta_{H \text { out }}+C_{2}=0
$$

with

$$
\begin{aligned}
& C_{1}=\left(\Delta_{E}+\Delta_{C}\right)-\theta_{\mathrm{L} 0}-\theta_{\mathrm{ao}}-\left(K_{H} P_{H P} / \dot{m}_{L} \mathcal{C}_{W}\right), \\
& C_{2}=\theta_{L 0} \theta_{\mathrm{ao}}-\theta_{L 0}\left(\Delta_{E}+\Delta_{C}\right)-\left(K_{H} P_{H P} / \dot{m}_{L} \mathcal{C}_{W}\right)\left(\Delta_{C}+273\right) .
\end{aligned}
$$

Hence, the unknown temperature $\theta_{H \text { out }}$ is one of the two solutions of the second-order Eq. (A7) that satisfies the requirement of a positive temperature gradient in the water circuit. When the mass flow rate $\dot{m}_{L}$ in the water circuit is zero, the temperature $\theta_{H \text { out }}$ at the condenser outlet is not computed and is set equal to its numerical value at the beginning of the time step. Setting $C_{R}\left(\mathrm{~J}-\mathrm{kg}^{-3}\right)$ equal to the equivalent heat capacity of the water and steel radiator system, and using $\dot{m}_{\mathrm{RAD}}$ for the water mass-flow rate through the radiator $\left(\mathrm{kg}^{-1} \mathrm{~s}^{-1}\right)$, the heating power is $\dot{m}_{R A D} c_{W}\left(\theta_{R \text { in }}-\theta_{R \text { out }}\right)$. Since

$$
\theta_{H}=\left(\theta_{R \text { in }}+\theta_{R \text { out }}\right) / 2,
$$

the radiator equation is

$$
\left.C_{R}\left(\mathrm{~d} \theta_{H} / \mathrm{d} t\right)=2 \dot{m}_{\mathrm{RAD}} C_{W}\left(\theta_{R} \text { in }-\theta_{H}\right)-\dot{Q}_{N}\left(\theta_{H}-\theta_{R \mathrm{1}}\right) /\left(\theta_{H}-\theta_{R 1}\right)_{N}\right]^{4 / 3} .
$$

The outlet temperature $\theta_{R \text { out }}$ can then be computed from Eq. (A10).

In a storage tank with two equivalent sections (Fig. 7) the energy balance in the top section is

$$
\frac{1}{2} m_{S} c_{W}\left(\mathrm{~d} \theta_{S 2} / \mathrm{d} t\right)=\gamma \dot{m}_{L P} c_{W} \xi_{S}\left(\theta_{S \text { in }}-\theta_{S 2}\right)-\dot{m}_{\mathrm{SAN}} c_{W}\left(\theta_{S 2}-\theta_{S 1}\right)-1 / R_{S}\left(\theta_{S 2}-\theta_{R 1}\right)
$$

In the bottom section the energy balance is

$$
m_{S} / 2 c_{W}\left(\mathrm{~d} \theta_{S 1} / \mathrm{d} t\right)=(1-\gamma) \dot{m}_{L P} c_{W} \xi_{S}\left(\theta_{S} \text { in }-\theta_{S 1}\right)-\dot{m}_{\mathrm{SAN}} c_{W}\left(\theta_{S 1}-\theta_{W i}\right)+\gamma \dot{m}_{L P} c_{W} \xi_{S}\left(\theta_{S 2}-\theta_{S 1}\right)-1 / R_{S}\left(\theta_{S 1}-\theta_{R 1}\right),
$$

where $m_{S}$ is the mass of water in the storage $(\mathrm{kg}), c_{W}$ is the water heat capacity $\left(\mathrm{J}-\mathrm{kg}^{-1}-\mathrm{K}^{-1}\right), \theta_{S 1}$ and $\theta_{S 2}$ are, respectively, the water temperatures in the bottom and top sections $\left({ }^{\circ} \mathrm{C}\right), \gamma$ is a logical variable defined as $\gamma=1$ if

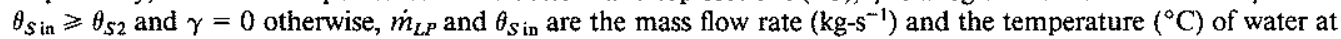
the storage-exchanger inlet, $\dot{m}_{\mathrm{SAN}}$ is the hot water mass-flow rate $\left(\mathrm{kg}^{-1} \mathrm{~s}^{-1}\right), R_{S}$ is the thermal resistance of the halfstorage tank (W-K $\left.\mathrm{K}^{-1}\right)^{-1}, \theta_{R:}$ is the first room temperature $\left({ }^{\circ} \mathrm{C}\right)$, assuming that the storage tank is located in the room, $\xi_{S}$ is the exchanger effectiveness $(-), \theta_{W i}$ is the cold water-inlet temperature $\left({ }^{\circ} \mathrm{C}\right)$.

Finally the temperature $\theta_{S \text { out }}$ requested to describe the next sub-system is

$$
\theta_{S \text { out }}=\xi_{S} \theta_{S 1}+\left(1-\xi_{S}\right) \theta_{S \text { in }} .
$$

The equations describing the room behaviour are

$$
\begin{gathered}
C_{\mathrm{AIR}}\left(\mathrm{d} \theta_{R} / \mathrm{d} t\right)=\dot{Q}+\left(\theta_{W}+\theta_{R}\right) /\left(R_{I}+R_{1}+R_{W} / 2\right)+\left(\theta_{\mathrm{ao}}-\theta_{R}\right) / R_{F}, \\
C_{\mathrm{WALL}}\left(\mathrm{d} \theta_{W} / \mathrm{d} t\right)=\left(\theta_{R}-\theta_{W}\right) /\left(R_{I}+R_{1}+R_{W} / 2\right)+\left(\theta_{\mathrm{ao}}-\theta_{W}\right) /\left(R_{O}+R_{2}+R_{W} / 2\right) .
\end{gathered}
$$

where $\theta_{W}$ is the wall temperature $\left({ }^{\circ} \mathrm{C}\right), C_{\mathrm{AIR}}$ and $C_{\text {WALL }}$ are, respectively, the thermal capacities $\left(\mathrm{J}-\mathrm{K}^{-1}\right)$ of the air and of the walls, $R_{I}$ and $R_{O}$ are, respectively, the surface thermal resistances $\left[\left(\mathrm{W}-\mathrm{K}^{-1}\right)^{-1}\right]$ for inside and outside air convection, $R_{1}$ and $R_{2}$ are, respectively, the thermal resistances $\left[\left(\mathrm{W}-\mathrm{K}^{-1}\right)^{-1}\right]$ of the inside and outside insulation material, $R_{W}$ is the thermal resistance of the walls $\left[\left(\mathrm{W}-\mathrm{K}^{-1}\right)^{-1}\right], R_{F}$ is the thermal resistance of the windows $\left[\left(\mathrm{W}-\mathrm{K}^{-1}\right)^{-1}\right], \dot{Q}$ is the heating power $(\mathrm{W})$ from the radiator or floor heating.

The model may be improved by the addition of the solar gain $\dot{Q}_{\mathrm{suN}}(W)$ through windows.

The size and heating power of the radiator or of the floor heating system are determined by the room heat losses: 